\title{
Voltage stability analysis based on multi-objective optimal reactive power dispatch under various contingency
}

\author{
Youssouf Amrane, Ali Elmaouhab, Mohamed Boudour, and Ahmed Amine Ladjici \\ Laboratory of Electrical and Industrial Systems, \\ University of Science and Technology HouariBoumediene, Algiers. Algeria \\ yamrane@usthb.dz,aelmaouhab@yahoo.fr,mboudour@ieee.org, aladjici@usthb.dz
}

\begin{abstract}
An effective allocation of the reactive power in an electrical network aims generally to improve the voltage profile and to control transmission power losses. The present paper proposes the application of an efficient hybrid method combining two evolutionary search techniques. The technique is based on Particle Swarm Optimization (PSO) algorithm and Gravitational Search Algorithm (GSA) to solve the Optimal Reactive Power Planning (ORPP) problem for energy losses cost minimization of Algerian electric power system using the static Var Compensator devices (SVC). To ensure viability of the power system in contingency cases, various critical situations are simulated in order to prevent and prepare the power system to face such situations. The proposed program handles most changes that can occur in to the power system (heavy load, losing a large generator, losing a critical line ...etc.). The proposed method is applied to solve the ORPP problem on the equivalent Algerian electric power system 114bus. Moreover, the obtained results are compared, with PSO and GSA, separately. The results obtained by the proposed method show it's effectiveness for improving the reactive power planning problem.

Index Terms: Optimal reactive power planning, Hybrid PSO-GSA, Stability Index, Equivalent Algerian electric power system.
\end{abstract}

\section{Introduction}

Through adjusting voltage generator, reactive power generator, transformer taps, and reactive power sources (capacitive or inductive banks, FACTS devices, etc.), the reactive power planning can reduce voltage deviations and active power losses. And in the same time maximizing voltage stability margin [1-2]. Since the generator reactive power, generator voltages, the transformer ratios and reactive power sources are continuous, the optimization problem is a nonconvex nonlinear programming problem (NLP). To solve such problem many conventional methods [35], like stochastic search methods [5-11] and hybrid conventional-stochastic methods [1], have been proposed.

To insure the power system security, the OPRPP problem is associated with the contingency analysis problem. The contingency analysis, which is a well-known function in power system planning and operation [11-15], is used later to predict the contingencies which make system violated and rank the contingencies according to their relative severity. An outage of a transmission line, capacitor bank or transformer may lead to over loads in other branches and sudden system voltage rise or drop. This may lead to complete blackout. In this paper, three critical contingency cases are studied, these are: 1) Heavy load, 2) Lose a large Generator, 3) Lose a critical line. These cases are studied in a way to guarantee: i) The system stability after the increase of the power system load (voltage level, active and reactive power and load tap changer value are in the secure range), ii) The stability system maintainability after the outage of a large generator and a critical line, iii) a better location choice of the SVC's devices is for improving the network voltage level and stability.

In this paper, the voltage instability analysis study, which is one of the critical issues in electric power system [16-17], is also considered in a way to identify the critical buses to locate the SVC's devices and the critical lines for the contingency study purpose. For this purpose, three different stability indexes namely Fast Voltage Stability Index (FVSI)[18], Line stability index (Lmn 19] and Line Stability Factor(LPQ) [20] are used. 
To solve the ORPP problem, which is a nonlinear optimization problem, we have opted to use a hybrid meta-heuristic technique combining a particle swarm optimization method and the gravitational search algorithm (PSO-GSA) [21].In the first part of this method, the PSO is used. This method is a stochastic search technique developed by Kennedy and Eberhart [22] and has been found to be robust and flexible in solving optimization problem, because it can generate a high quality solution within shorter calculation time and more stable convergence characteristic than other stochastic methods. In the second part, the GSA method is used [23]. It is a novel optimization method based on the law of gravity and mass interactions. It has good ability to search for the global optimum. However, these methods suffer from its low computational speed. Hence, the use of the hybridization PSO \& GSA aims to give to the new algorithm more effective and efficient. Also, it can find the optimal solution with less computational time with more accuracy. The principle of the hybrid technique used in this paper is base on the exploitation of the feature of the GSA in the initial stages of the search process, and the exploring feature of the PSO during the later stages of the algorithm [21]. In [21], IrajKheirizad have used use twentythree benchmark functions to validate the performance of the PSOGSA algorithm and was compared to standard PSO and GSA. The obtained results show that the number of functions performed well by the PSOGSA is nearly twice of functions performed by PSO and GSA. This comparison shows the robustness and the effectiveness of the PSO and GSA. The results also have shown that the convergence speed of PSOGSA is faster with stable convergence characteristic than other stochastic methods [21]. A state of the art of the use of the proposed method in several electrical engineering domains is presented in the appendix section.

The proposed approach has been applied to the ORPP problems using SVC's device for the equivalent Algerian electric power system 114-bus. Three stability index methods, FVSI, Lmn, and $L P Q$ are used to identify the weakest buses and lines where to install the SVC's devices.

\section{Appendix A}

This section contains a state of art of the hybrid PSOGSA technique surfaced in the recent stateof-the-art literature:

Table A1. A state of art of the hybrid PSOGSA technique.

\begin{tabular}{|c|l|l|l|}
\hline Reference & \multicolumn{1}{|c|}{ Paper Title } & Year \\
\hline$[25]$ & $\begin{array}{l}\text {-Optimal location and } \\
\text { optimal size of the SVC. }\end{array}$ & $\begin{array}{l}\text { 1-A Novel Algorithm for Optimal } \\
\text { Location of FACTS Devices in } \\
\text { Power System Planning. }\end{array}$ & 2008 \\
{$[30]$} & $\begin{array}{l}\text { 2-Optimal Location and Sizing of } \\
\text { Multiple Static VAr Compensators } \\
\text { for Voltage Risk Assessment }\end{array}$ & 2014 \\
& $\begin{array}{l}\text { Using Hybrid PSO-GSA } \\
\text { Algorithm. }\end{array}$ & 2014 \\
\hline$[26]$ & $\begin{array}{l}\text { Taktimal tuning of } \\
\text { fuzzy controllers (T-S-K } \\
\text { PI-FCs). }\end{array}$ & $\begin{array}{l}\text {-Adaptive Hybrid Particle Swarm } \\
\text { Optimization- } \\
\text { Search Algorithm for Fuzzy } \\
\text { Controller Tuning. }\end{array}$ & 2013 \\
\hline$[27]$ & $\begin{array}{l}\text {-Static State Estimation } \\
\text { (SE) problem. }\end{array}$ & $\begin{array}{l}\text {-Optimal static state estimation } \\
\text { using improved particle swarm } \\
\text { optimization and gravitational } \\
\text { search algorithm. }\end{array}$ & 2 \\
\hline
\end{tabular}




\begin{tabular}{|c|c|c|c|}
\hline [28] & $\begin{array}{l}\text {-Optimal reactive power } \\
\text { dispatch (ORPD) } \\
\text { problem for real power } \\
\text { loss and the bus voltage } \\
\text { deviations minimization. }\end{array}$ & $\begin{array}{l}\text {-A New Hybrid PSOGSA } \\
\text { Algorithm for Solving Optimal } \\
\text { Reactive Power Dispatch Problem. }\end{array}$ & 2014 \\
\hline [29] & $\begin{array}{l}\text {-Optimal path planning } \\
\text { algorithm for mobile } \\
\text { robots. }\end{array}$ & $\begin{array}{l}\text {-Hybrid PSO-GSA Robot Path } \\
\text { Planning Algorithm in Static } \\
\text { Environments with Danger Zones. }\end{array}$ & 2013 \\
\hline [31] & $\begin{array}{l}\text {-Economic Load } \\
\text { Dispatch Problem (ELD) } \\
\text { problem. }\end{array}$ & $\begin{array}{l}\text {-Application of New Hybrid } \\
\text { Particle Swarm Optimization and } \\
\text { Gravitational Search Algorithm } \\
\text { for Non Convex Economic Load } \\
\text { Dispatch Problem. } \\
\text {-A Novel Hybrid PSO-GSA } \\
\text { Method for Non-convex Economic } \\
\text { Dispatch Problems. }\end{array}$ & 2013 \\
\hline [33] & $\begin{array}{l}\text {-Economic emission load } \\
\text { dispatch } \\
\text { problems }\end{array}$ & $\begin{array}{l}\text {-A novel hybrid particle swarm } \\
\text { optimization and gravitational } \\
\text { search algorithm for solving } \\
\text { economic emission load dispatch } \\
\text { problems with various practical } \\
\text { constraints }\end{array}$ & 2014 \\
\hline
\end{tabular}

\section{Problem Formulation}

In this paper, the global objective function of the ORPP problem aims to minimize two objective functions which are: 1) Minimization the Compensation devices amount, 2) minimization of Cost of energy losses, while satisfying several equality and inequality constraints.

The proposed formulation of the ORPP problem is expressed as follows:

$$
\min _{u, x} f_{V A R}(U, X) / \min _{u, x} f_{W c}(U, X)
$$

Subject to $\left\{\begin{array}{c}G(U, X)=0 \\ H(U, X) \leq 0 \\ U_{\text {min }} \leq U \leq U_{\text {max }} \\ X_{\text {min }} \leq X \leq X_{\text {max }}\end{array}\right.$

with:

$$
U=\left[V_{G}, T_{R}, Q_{C}\right] \& \quad X=\left[V_{L}, P_{G}, Q_{G}\right]
$$

\section{A. Problem objectives}

\section{A.1. Compensation devices investment cost minimization}

The total investment cost function of the compensation devices is composed by the fixed installation cost and the purchase cost. 
This function is considered as a linear function [24]:

$$
f_{V A R}(X, U)=\sum_{i=0}^{N \text { var }}\left(C_{f i}+C_{c i}\left|Q_{c i}\right|\right)
$$

\section{A.2. Cost of energy losses minimization function}

The objective function of the cost of energy losses is represented as [24]:

$$
f_{W c}=h \sum_{i \in N_{L i}} d_{i}\left[G_{k}(i, j)\left(V_{i}^{2}+V_{j}^{2}+2 V_{i} V_{j} \cos \left(\theta_{i}-\theta_{j}\right)\right]\right.
$$

Where $d$ is the duration of load level I (see Table1).

\section{A.3. Proposed objective Function}

The proposed objective function is as follow [24]:

$$
f_{\text {cost }}=f_{W c}+f_{V A R}
$$

\section{B. System constraints}

\section{B.1. Equality constraints}

Equality constraints represent typical load flow equations as follows:

$$
\begin{aligned}
& P_{G j}-P_{D i}-V_{i} \sum_{j=1}^{N B} V_{j}\left(G_{i j} \cos \theta_{i j}+B_{i j} \sin \theta_{i j}\right)=0 i=1,2 \ldots N_{b u s} \\
& Q_{G j}-Q_{D i}-V_{i} \sum_{j=1}^{N B} V_{j}\left(G_{i j} \sin \theta_{i j}-B_{i j} \cos \theta_{i j}\right)=0 j=1,2 \ldots N_{b u s}
\end{aligned}
$$

\section{B.2. Inequality constraints}

The inequality constraints represent the system operating constraints.

Generator constraints: The generator voltages $V_{G}$ and reactive power outputs $Q_{G}$ are restricted by their upper and lower limits as follows:

$$
\begin{aligned}
& V_{G i}^{\min } \leq V_{G i} \leq V_{G i}^{\max } i=1,2, \ldots N_{G} \\
& Q_{G i}^{\min } \leq Q_{g i} \leq Q_{G i}^{\max } i=1,2 \ldots N_{G}
\end{aligned}
$$

Switchable VAR constraints: Switchable VAR compensations are restricted by their lower and upper limits as follows:

$$
Q_{C i}^{\min } \leq Q_{C i} \leq Q_{C i}^{\max } i=1,2, \ldots N_{c}
$$

Transformer constraints: transformer tap settings are bounded as follow:

$$
T_{i}^{\min } \leq T_{i} \leq T_{i}^{\max } i=1,2, \ldots N_{T}
$$

4-Security constraints: these constraints include the constraints of voltage at load $V_{L}$ bus and transmission line loading $\left\{S_{t}^{\text {from }}, S_{t}^{\text {to }}\right\}$ as follows:

$$
\begin{aligned}
& V_{L i}^{\text {min }} \leq V_{L i} \leq V_{L i}^{\max } i=1,2, \ldots N_{\text {Load }} \\
& \left\{S_{t}^{\text {from }}, S_{t}^{\text {to }}\right\} \leq S_{\max }^{i} i=1,2, \ldots N_{L i}
\end{aligned}
$$

\section{Identification of critical buses and lines}

The Stability indices have been usually used in power system for the purpose of voltage stability valuation. They can be an indicator to assess the state of a power system, whether it is healthy or stressed. The purpose of voltage stability index is to determine the point of voltage instability, the weakest bus in the system and the critical line. In this paper, a new voltage stability 
index is proposed to evaluate the line stability condition in a power system and to identify the system critical buses and lines.

The proposed stability indexes are as follows:

\section{A. Fast Voltage Stability Index (FVSII)}

The Fast Voltage Stability Index FVSI is proposed by I. Musirin et al [18]. It is formulated on the base of a power transmission concept in a single line.

The mathematical formulation of the FVSI is so simple that it can be calculated on-line. Taking the symbols $i$ as the sending bus and $j$ as the receiving bus. Hence, the fast voltage stability index $(F V S I)$ can be represented as:

$$
F V S I=\frac{4 Z^{2} Q_{j} X}{V_{i}^{2} X}
$$

\section{B. Line Stability Index (Lmn)}

The line stability index Lmn proposed by Moghavvemi et al. [19] is formulated on the base of a power transmission concept in a single line.

The line stability index can be reproduced as:

$$
L m n_{i j}=\frac{4 Q_{r} X}{\left[\left|V_{i}\right| \sin (\Theta-\delta)\right]^{2}}
$$

\section{Line Stability Factor ( $L P Q)$.}

The $L Q P$ was proposed by A. Mohamed et al [20]. It was used in the comparison since this factor is more sensitive to a reactive power change. $L Q P$ is calculated as:

$$
L P Q=4\left(\frac{X}{V_{i}^{2}}\right)\left(\frac{X}{V_{i}^{2}} P_{i}^{2}+Q_{j}\right)
$$

The value of voltage stability index must to be kept between 0 and 1 . If it is close to 1 , it means that it is near to the instability point. Consequently, the voltage instability could occur. And if it is close to 0 , it means that the system is very secure.

The steps implemented for identifying the critical buses and lines are taken from [7].

\section{Proposed method Hybrid PSO-GSA technique}

The hybrid algorithm proposed in this study is a combination of PSO algorithm and GS algorithm. The PSOGSA is a new hybrid method which has been proposed by S.Mirjalili et al. in 2010 [21]. The basic idea of PSOGSA is to combine the ability of social thinking (gbest) in PSO [22] with the local search capability of GSA [23]. To combine these algorithms; the following formulation is used [22]:

$$
\begin{aligned}
& V_{i}(t+1)=w \times V_{i}(t)+c_{1}{ }^{\prime} \times \text { rand } \times a c_{i}(t)+ \\
& c_{2}{ }^{\prime} \times \text { rand } \times\left(\text { gbest }+X_{i}(t)\right)
\end{aligned}
$$

The positions of particles are updated at each iteration as follow [21]:

$$
X_{i}(t+1)=X_{i}(t)+V_{i}(t+1)
$$

The flowchart of PSO-GSA is shown in Figure 1.

The details of the PSO-GSA based optimization algorithm are as follows:

Step 1: A set of initial populations are created randomly within the minimum and maximum limits of the control variables. This initial populations is chosen as a parent populations

Step 2: The objective function for each agent in the initial population is evaluated.

Step 3: Calculate Gravitational force, gravitational constant and resultant forces among agents using (19), (20), and (21) respectively: 


$$
\begin{aligned}
& \longrightarrow F_{i j}^{d}(t)=G(t) \frac{M_{p i}(t) \times M_{a j}(t)}{R_{i j}(t)+\varepsilon}\left(x_{j}^{d}(t)-x_{i}^{d}(t)\right) \\
& \rightarrow G(t)=G_{0} \times \exp (-\alpha \times \text { iter / max iter }) \\
& \rightarrow F_{i}^{d}(t)=\sum_{\substack{j=1 \\
j \neq i}}^{N} \text { rand }_{j} F_{i j}^{d}(t)
\end{aligned}
$$

Step 4: Calculate $M$ acceleration for all agents of particles as defined in (22).

$$
a c_{i}^{d}(t)=\frac{F_{i}^{d}(t)}{M_{i i}(t)^{\prime}}
$$

Step 5: Calculate velocities of all agents using (17).

Step 6: Update position of each agent according to (18).

Step 7: The objective function for the new searching points and the evaluation values are calculated. The process of updating velocities and positions will be stopped when the end criterion it met.

Step 8: If the stopping criterion is met (which means that the maximum number of generation is reached or the optimal point is achieved), the results is printed. Otherwise, go to Step 2.

Step 9: Return the best solution.

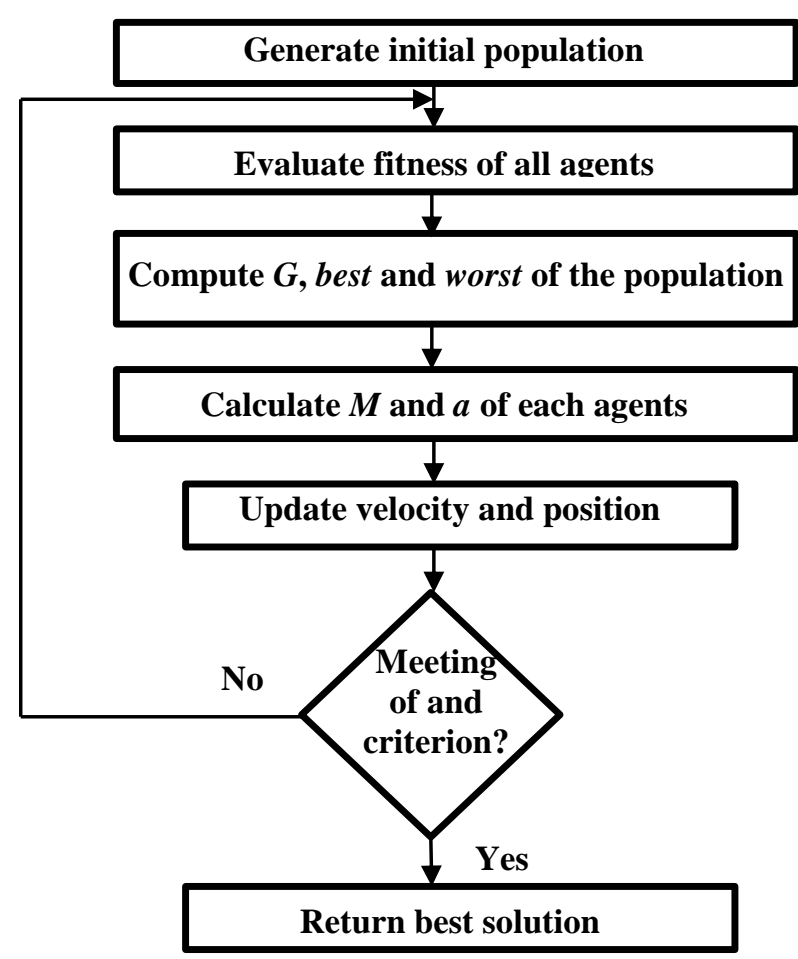

Figure 1. Flow Chart of the PSO-GSA algorithm.

\section{A. PSOGSA for ORPP problem}

In the ORPP problem, the elements of the solution consist of all control variables, namely, generator bus voltages $(\mathrm{V})$, the transformer tap-setting $(\mathrm{T})$ and the reactive power generation $\left(Q_{c}\right)$. The proposed objective function can minimize three objective functions by satisfying the constraints given by equations (8) to (13). For each individual, the dependent variables presented 
in (9, 12 and 13) and the equality constraints given by equations (6) and (7) are satisfied by running the power flow Newton-Raphson algorithm. The control variables presented in $(8,10$ and 11) are self-controlled. And the dependent variables are added in the quadratic penalty terms to the objective function in order to keep their final value close to their operating limits.

$$
F=f_{\cos t}+\sigma_{v_{i}} \sum_{i o N_{P Q}}\left(V_{i}-V_{i}^{l i m}\right)^{2}+\sigma_{Q_{G i}} \sum_{i o N_{G}}\left(Q_{G i}-Q_{G i}^{l i m}\right)^{2}+\sigma_{S_{i}^{t}} \sum_{i o N_{2 L i}}\left(S_{i}^{t}-S_{t}^{l i m}\right)^{2}
$$

In the above objective function $V_{i}^{\text {lim }}, Q_{G i}^{\text {lim }} a n d S_{i}^{\text {lim }}$ are defined in the following equations.

$$
\begin{aligned}
& V_{i}^{\text {lim }}=\left\{\begin{array}{c}
V_{i}^{\min }, \text { if } V_{i}<V_{i}^{\min } \\
V_{i}^{\max }, \text { if } V_{i}>V_{i}^{\max } \\
V_{i}, \text { if } V_{i}^{\min }<V_{i}<V_{i}^{\max }
\end{array}\right\} Q_{G i}^{\text {lim }}=\left\{\begin{array}{c}
Q_{G i}^{\min }, \text { if } Q_{G i}<Q_{G i}^{\min } \\
Q_{G i}^{\max } \text {, if } Q_{G i}>Q_{G i}^{\max } \\
Q_{G i}, \text { if } Q_{G i}^{\min }<Q_{G i}<Q_{G i}^{\max }
\end{array}\right\} \\
& S_{i}^{\lim }=\left\{\begin{array}{c}
S_{i}^{\min } \text {, if } S_{i}^{t}<S_{i}^{\min } \\
S_{i}^{\max }, \text { if } S_{i}^{t}>P_{G 1}^{\max } \\
S_{i}^{t}, \text { if } S_{i}^{\min }<S_{i}^{t}<S_{i}^{\max }
\end{array}\right\}
\end{aligned}
$$

\section{SVC Model}

The SVC is defined as a shunt connected static Var generator or consumer, whose output is adjusted to exchange capacitive or inductive current in order to control specific parameters of the power system, typically bus voltage. In this paper, the SVC is modeled as a variable shunt reactive susceptance $j b_{s v c}$ installed at the node $i$. In this case, only one term of the nodal admittances, corresponding to the node where the SVC is connected (see Figure 2) [1], matrix is modified.

The difference between the line susceptance before and after the addition of SVC can be expressed as:

The admittance matrix $Y_{\text {bus }}$ before the addition of SVC:

$$
\underline{Y}_{b u s}=\left[\begin{array}{cc}
\underline{y}_{i j}+\frac{\underline{y}_{i j 0}}{2} & -\underline{y}_{i j} \\
-\underline{y}_{i j} & \underline{y}_{i j}+\frac{\underline{y}_{i j 0}}{2}
\end{array}\right]
$$

The new system admittance matrix $Y^{\prime}$ bus can be updated as:

$$
\underline{Y}_{b u s}^{\prime}=\left[\begin{array}{cc}
\underline{y}_{i j}+\frac{\underline{y}_{i j 0}}{2}+\underline{y}_{S V C} & -\underline{y}_{i j} \\
-\underline{y}_{i j} & \underline{y}_{i j}+\frac{\underline{y}_{i j 0}}{2}
\end{array}\right]
$$

where

$$
\begin{aligned}
& y_{S V C}=j b_{S V C} \\
& y_{i j}=G_{i j}+j B_{i j} \text { and } \quad G_{i j}=\frac{R_{i j}^{\text {line }}}{\left(R_{i j}^{\text {line }}\right)^{2}+\left(X_{i j}^{\text {line }}\right)^{2}}, B_{i j}=-\frac{X_{i j}^{\text {line }}}{\left(R_{i j}^{\text {line }}\right)^{2}+\left(X_{i j}^{\text {line }}\right)^{2}}
\end{aligned}
$$


Because $Y^{\prime}$ bus has to be updated for different size of SVC $\left(b_{S V C}\right)$, the above formulation is applied at each iteration [1].

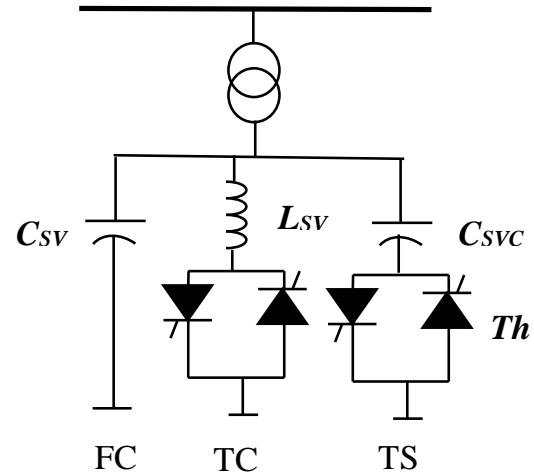

a. SVC configuration.

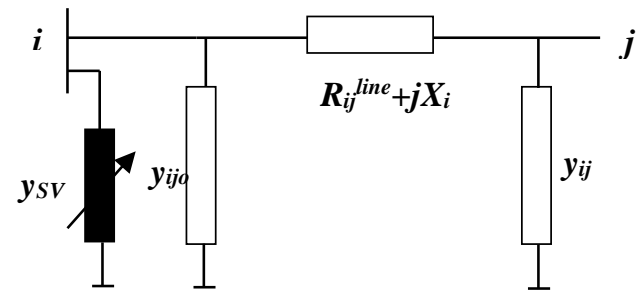

b) SVC Equivalent model.

Figure 2. Static VAR compensator (SVC).

\section{Simulation Results}

In order to verify the effectiveness of the proposed approach, the hybrid particle swarm optimization and gravitational search algorithm (PSOSGA) has been tested on the equivalent Algerian electric power system 114-bus $(220 / 60 \mathrm{kV})$. For comparison purpose, two other algorithms are also implemented for solving the problem, namely Particle Swarm Optimization (PSO) and Gravitational Search Algorithm (GSA). Table 2 shows the parameters, number of iterations and population size of these algorithms. The penalty factors in (25) are listed in Table 3. The programs have been written in MATLAB-7 language and executed on a $2.91 \mathrm{GHz} \mathrm{CPU}$ dual -core with 4 GO RAM.

Table 1. Duration of load level.

\begin{tabular}{c|cccccc}
\hline Cases & Case1 & Case2 & \multicolumn{2}{c}{ Case3 } & Sace4 & Case5 \\
\hline di (hour) & 8760 & 8760 & 4380 & 4380 & 8760 & 8760 \\
\hline
\end{tabular}

Table 2. Minimization parameter setting.

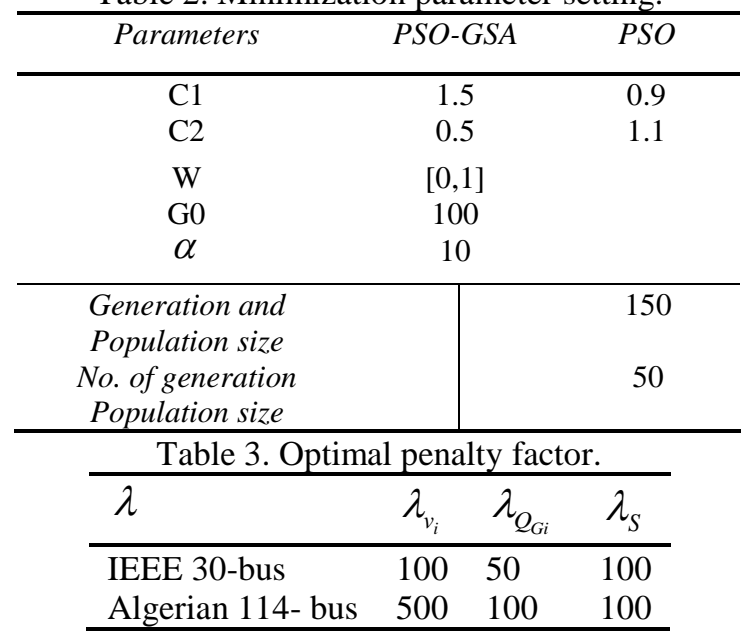

To validate the effectiveness of proposed approach; five different study cases are considered (see Table 4): 
Table 4. Study cases.

\begin{tabular}{l|l}
\cline { 2 - 2 } Cases & \multicolumn{1}{c}{ Algerian 114-bus } \\
\hline Cases 1 & Base case (nominal point). \\
\hline Cases 2 & Uniform load variation of 20 per cent from base case. \\
\hline Cases 3 & 1- Base case \\
& 2-Uniform load variation of 15 per cent from base case. \\
\hline Cases 4 & Uniform load variation of 15 per cent from base case+ suppression of Generator 11. \\
\hline Cases 5 & Uniform load variation of 15 per cent from base case+ suppression of line 17-27. \\
\hline
\end{tabular}

The real power saving $P_{\text {save }}$ and the annual cost saving $W_{c}^{\text {save }}$ is calculated to compare the performance of the proposed algorithm with PSO and GSA methods.

$$
\text { with } P_{\text {save }} \%=\frac{P_{\text {loss }}^{\text {init }}-P_{\text {loss }}^{\text {opt }}}{P_{\text {loss }}^{\text {init }}} \text { And } W_{c}^{\text {save }}=h d_{i}\left(P_{\text {loss }}^{\text {init }}-P_{\text {loss }}^{\text {opt }}\right) * 10^{5}
$$

\section{A. Weakest buses identification}

Table 5 ranks the top 15 weakest buses and lines for the equivalent Algerian electric power system 114-bus. The chosen buses which will receive the compensations devices are listed in Table 6.

Table 5. Stability index results for the Algerian 114-bus system.

\begin{tabular}{|c|c|c|c|c|c|c|c|c|c|}
\hline \multirow[b]{2}{*}{ Rank } & \multicolumn{4}{|c|}{ Most Critical Nodes } & \multicolumn{5}{|c|}{ Most Critical Lines } \\
\hline & $\begin{array}{c}\text { Bus } \\
\text { Number }\end{array}$ & $\begin{array}{c}\mathrm{Q}_{\text {MaxFVSI }} \\
(\mathrm{Pu})\end{array}$ & $\begin{array}{c}\mathrm{Q}_{\text {MaxLMN }} \\
(\mathrm{Pu})\end{array}$ & $\begin{array}{c}\mathrm{Q}_{\mathrm{MaxLPQ}} \\
(\mathrm{Pu})\end{array}$ & $\begin{array}{c}\text { Lines } \\
\text { Number }\end{array}$ & $\begin{array}{c}\text { Lines } \\
\text { From-to }\end{array}$ & FVSI & LMN & LPQ \\
\hline$\underline{1}$ & $\underline{67}$ & $\underline{0.2691}$ & $\underline{0.2591}$ & $\underline{0.2791}$ & $\underline{27}$ & $\underline{17--27}$ & $\underline{0.9999}$ & $\underline{9,9999}$ & $\underline{0.9999}$ \\
\hline$\underline{2}$ & $\underline{43}$ & $\underline{0.36076}$ & $\underline{0.37076}$ & $\underline{0.37076}$ & 10 & $15--16$ & 0.9999 & 0.9999 & 0.9998 \\
\hline$\underline{3}$ & $\underline{66}$ & $\underline{0.38422}$ & $\underline{0.36422}$ & $\underline{0.36422}$ & 72 & $24--25$ & 0.9997 & 0.9999 & 0.9998 \\
\hline$\underline{4}$ & $\underline{93}$ & $\underline{0.41}$ & $\underline{0.42}$ & $\underline{0.46}$ & 43 & $42--48$ & 0.9995 & 0.9999 & 0.9998 \\
\hline$\underline{5}$ & $\underline{77}$ & $\underline{0.41346}$ & $\underline{0.44346}$ & $\underline{0.41346}$ & 33 & $21--60$ & 0.9995 & 0.9998 & 0.9998 \\
\hline$\underline{6}$ & $\underline{41}$ & $\underline{0.47024}$ & $\underline{0.48024}$ & $\underline{0.50024}$ & 25 & $17--21$ & 0.9995 & 0.9997 & 0.9998 \\
\hline$\underline{7}$ & $\underline{50}$ & $\underline{0.48564}$ & $\underline{0.48564}$ & $\underline{0.52564}$ & 146 & 92--93 & 0.9999 & 0.9995 & 0.9995 \\
\hline 8 & 55 & 0.49038 & 0.50038 & 0.52038 & 61 & $35--29$ & 0.9995 & 0.9994 & 0.9995 \\
\hline 9 & 51 & 0.49782 & 0.51782 & 0.50782 & 28 & $17--31$ & 0.9995 & 0.9994 & 0.9993 \\
\hline 10 & 89 & 0.51294 & 0.51294 & 0.51294 & 112 & 49--41 & 0.9993 & 0.9994 & 0.9991 \\
\hline 11 & 56 & 0.5164 & 0.5164 & 0.5264 & 26 & $17--72$ & 0.9998 & 0.9994 & 0.9991 \\
\hline 12 & 69 & 0.5182 & 0.5182 & 0.5182 & 117 & 85--87 & 0.9992 & 0.9991 & 0.9998 \\
\hline 13 & 68 & 0.5291 & 0.5491 & 0.5991 & 142 & 99--102 & 0.9995 & 0.9991 & 0.9991 \\
\hline 14 & 12 & 0.5373 & 0.5173 & 0.5373 & 153 & 110--112 & 0.9990 & 0.9990 & 0.9996 \\
\hline 15 & 54 & 0.5582 & 0.5682 & 0.5682 & 14 & $8--4$ & 0.9990 & 0.9990 & 0.9993 \\
\hline
\end{tabular}

Table 6. Compensation devices location.

Algerian 114-bus $41 ; 43 ; 50 ; 66 ; 67 ; 77 ; 93$

B. Algerian Electric Power System 114-Bus simulation results

In this section the comparison of proposed algorithm runs on the equivalent Algerian electric power system $(220 / 60 \mathrm{kV})$. The system consists of 175 transmission lines, 15 generator-buses, 99 load-bus, and 17 tap changer transformers. The switchable capacitor bank will be installed at bus bars 66 and 67, the total system real and reactive power demands are 3146.2 MW and 1799.4 Mvar. The Algerian power system data are given in Appendix B (Tables B.1 to B.3). The control variable limits and the description of the test systems are listed respectively in Tables 7 and 8. 
Table 7. Setting of control variables.

\begin{tabular}{ccc}
\hline \multicolumn{3}{l}{ Algerian 114- bus } \\
\hline Var & Min & Max \\
\hline $\mathrm{T}($ P.u $)$ & 0.9 & 1.1 \\
$\mathrm{~V}_{\mathrm{G}}($ P.u $)$ & 0.9 & 1.1 \\
$\mathrm{Q}_{\mathrm{c}}(\mathrm{P} . \mathrm{u})$ & 0 & 0.5 \\
\hline
\end{tabular}

Table8: Description of test systems.

\begin{tabular}{cc}
\hline Variables & Algerian 114 -bus \\
\hline $\mathrm{P}_{\mathrm{g}}(\mathrm{MW})$ & 3146.2 \\
$\mathrm{Q}_{\mathrm{g}}(\mathrm{Mvar})$ & 1799.4 \\
$\mathrm{P}_{\text {loss }}(\mathrm{MW})$ & 67.4567 \\
$\mathrm{Q}_{\text {loss }}(\mathrm{MVAR})$ & 265.840 \\
\hline
\end{tabular}

Table 9 lists the optimal setting of control variables for this case for proposed PSO-GSA algorithm. From this table it can be seen that all control variables obtained by the proposed method are within the secure limits. In the other hand, the installation of reactive power is considered only for the most critical case (case 2, 3-2, 4 and 5) where the weakest buses become instable and need the reactive power to become stable.

The obtained load voltage profile of the Algerian 114- bus test system for all case studies obtained by proposed algorithm is shown in Figures 3. From the figure we can see all loads voltage magnitudes are within their minimum and maximum limits of 1.1 and 0.9 .

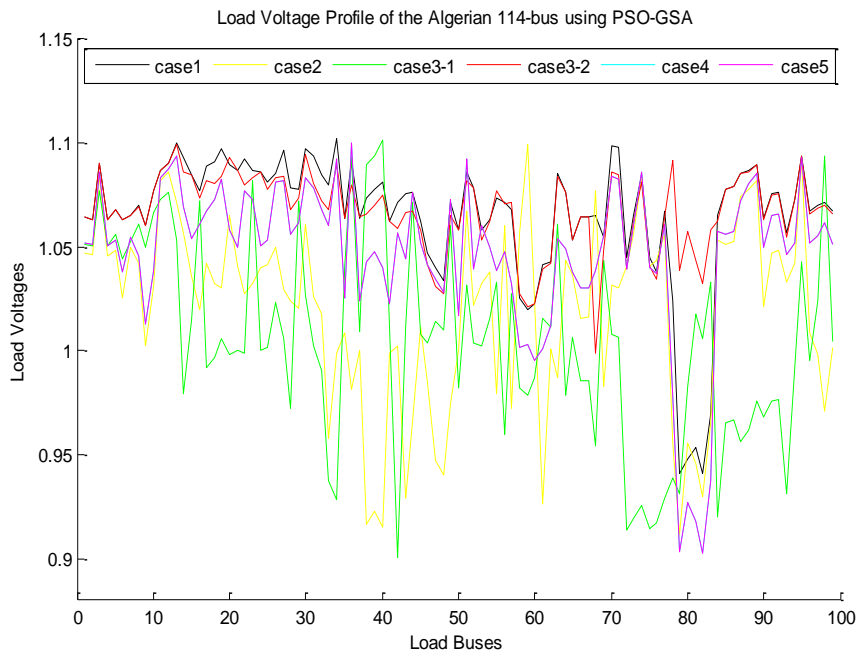

Figure 3. Load Voltage Profile of the Algerian 114-bus test system using PSO-GSA. 
Table 9. Optimal Setting of Control Variables for the Algerian 114-bus using hybrid PSO-GSA.

\begin{tabular}{|c|c|c|c|c|c|c|}
\hline \multicolumn{7}{|c|}{ Algerian-114bus (PSO-GSA) } \\
\hline Variables & Case1 & Case2 & Case3-1 & Case 3-2 & Case4 & Case5 \\
\hline $\mathrm{V}_{4}$ & 1,1000 & 1,0976 & 1,0882 & 1,0971 & 1,0996 & 1,1000 \\
\hline $\mathrm{V}_{5}$ & 1,0944 & 1,0866 & 1,0806 & 1,0858 & 1,0892 & 1,0896 \\
\hline $\mathrm{V}_{11}$ & 1,0776 & 1,0537 & 1,0731 & 1,0512 & 1,1000 & 1,0510 \\
\hline $\mathrm{V}_{15}$ & 1,1000 & 1,1000 & 1,0862 & 1,1000 & 1,0855 & 1,1000 \\
\hline $\mathrm{V}_{17}$ & 1,1000 & 1,0679 & 1,0158 & 1,0432 & 1,0123 & 1,0744 \\
\hline $\mathrm{V}_{19}$ & 1,0994 & 1,0327 & 1,0085 & 1,0308 & 1,0428 & 1,0850 \\
\hline $\mathrm{V}_{52}$ & 1,1000 & 1,0653 & 1,0356 & 1,0755 & 1,0386 & 1,0873 \\
\hline $\mathrm{V}_{22}$ & 1,1000 & 1,0592 & 1,0134 & 1,0728 & 1,0445 & 1,0806 \\
\hline $\mathrm{V}_{80}$ & 1,0667 & 1,0594 & 0,9085 & 1,0602 & 1,0804 & 1,0621 \\
\hline $\mathrm{V}_{83}$ & 1,0923 & 1,0960 & 0,9284 & 1,0995 & 1,0800 & 1,0995 \\
\hline $\mathrm{V}_{98}$ & 1,0946 & 1,0831 & 0,9643 & 1,0755 & 0.0000 & 1,0846 \\
\hline$V_{100}$ & 1,1000 & 1,1000 & 0,9552 & 1,1000 & 1,1000 & 1,1000 \\
\hline $\mathrm{V}_{101}$ & 1,0998 & 1,0958 & 0,9974 & 1,0943 & 1,1000 & 1,0988 \\
\hline $\mathrm{V}_{109}$ & 1,1000 & 1,1000 & 1,0491 & 1,1000 & 1,1000 & 1,1000 \\
\hline $\mathrm{V}_{111}$ & 1,0783 & 0,9812 & 1,1000 & 1,0978 & 1,0772 & 1,0700 \\
\hline $\mathrm{T}_{80-88}$ & 0,9337 & 0,9927 & 0,9000 & 1,0654 & 0,9000 & 0,9614 \\
\hline $\mathrm{T}_{81-90}$ & 1,1000 & 1,0566 & 0,9141 & 0,9712 & 1,0272 & 1,1000 \\
\hline $\mathrm{T}_{86-93}$ & 1,0487 & 1,0969 & 0,9000 & 1,0104 & 0,9795 & 1,1000 \\
\hline $\mathrm{T}_{42-41}$ & 0,9417 & 0,9887 & 1,1000 & 0,9274 & 0,9696 & 0,9105 \\
\hline $\mathrm{T}_{58-57}$ & 0,9654 & 0,9993 & 0,9018 & 0,9918 & 1,0495 & 0,9217 \\
\hline $\mathrm{T}_{44-43}$ & 0,9512 & 1,0310 & 0,9000 & 0,9557 & 0,9807 & 0,9440 \\
\hline $\mathrm{T}_{60-59}$ & 0,9814 & 0,9337 & 0,9573 & 0,9120 & 0,9800 & 0,9311 \\
\hline $\mathrm{T}_{64-63}$ & 0,9700 & 1,0830 & 0,9010 & 1,0332 & 1,0888 & 0,9789 \\
\hline $\mathrm{T}_{72-71}$ & 0,9693 & 1,0383 & 0,9001 & 0,9968 & 1,0087 & 0,9699 \\
\hline $\mathrm{T}_{17-18}$ & 0,9746 & 0,9656 & 0,9000 & 0,9037 & 0,9775 & 0,9463 \\
\hline $\mathrm{T}_{21-20}$ & 0,9851 & 0,9540 & 1,1000 & 0,9439 & 1,0341 & 0,9912 \\
\hline $\mathrm{T}_{27-26}$ & 0,9392 & 1,0187 & 0,9047 & 0,9284 & 1,0096 & 0,9028 \\
\hline $\mathrm{T}_{28-26}$ & 0,9989 & 1,0195 & 0,9902 & 1,0953 & 1,0783 & 0,9608 \\
\hline $\mathrm{T}_{31-30}$ & 0,9887 & 0,9980 & 0,9031 & 0,9565 & 1,0173 & 0,9672 \\
\hline $\mathrm{T}_{48-47}$ & 0,9772 & 1,0938 & 0,9000 & 0,9000 & 0,9919 & 0,9837 \\
\hline $\mathrm{T}_{74-76}$ & 0,9846 & 0,9269 & 1,0138 & 1,0765 & 1,0989 & 0,9740 \\
\hline $\mathrm{Q}_{\mathrm{c} 41}$ & 0,0000 & 0,1714 & 0,0000 & 0,4714 & 0,4992 & 0,0160 \\
\hline $\mathrm{Q}_{\mathrm{c} 43}$ & 0,0000 & 0,4841 & 0,0000 & 0,4781 & 0,3681 & 0,4954 \\
\hline $\mathrm{Q}_{\mathrm{c} 50}$ & 0,0000 & 0,1031 & 0,0236 & 0,0631 & 0,0384 & 0,0180 \\
\hline$Q_{c 66}$ & 0,0000 & 0,4852 & 0,0000 & 0,1160 & 0,4378 & 0,0536 \\
\hline $\mathrm{Q}_{\mathrm{c67}}$ & 0,0000 & 0,4984 & 0,0000 & 0,5000 & 0,3973 & 0,0658 \\
\hline$Q_{c 77}$ & 0,0000 & 0,0675 & 0,0003 & 0,0419 & 0,1326 & 0,0133 \\
\hline $\mathrm{Q}_{\mathrm{c} 93}$ & 0,0000 & 0,4999 & 0,4936 & 0,4985 & 0,0221 & 0,2362 \\
\hline
\end{tabular}


Tables 10, 11 and 12 present the results obtained for different cases of study by using GSA, PSO, and PSO-GSA methods respectively. In comparing the results, we can notice that the minimum active power losses in cases 2 to 5 obtained by the proposed method are considerably reduced with regard to the other methods. For example, for Case 1, the proposed method allows to reduce the active power losses $P_{\text {loss }}$ from 0.6745 p.u to 0,5905 p.u. And by using PSO and GSA the active power losses are reduced respectively to 0,5929p.u and 0,6000p.u. Also, for cases 2 to 5 we get further reduction of active power losses $\left(P_{\text {loss }}\right)$ when using the hybrid PSO-GSA method. From these results we can see that the minimum found by the proposed method is better than the PSO and GSA method when used separately. This comparison proves the superiority of the proposed method.

Furthermore, from the result presented in tables 10 to 12 , it can be noted that at the cases 1 (the base case) real power saving $\left(P^{\text {save }}\right)$ and the annual cost saving $\left(W c^{\text {save }}\right)$ fond by the hybrid PSO-GSA method are reduced by 1,$60880 ; 11,5310 ; 11,6960 \%$ and 0,$40643 ; 3,00968 ; 3,00950$ $\%$ respectively compared to the two comparison methods (PSO and GSA). On the other hand the minimum $P_{\text {loss, }}, P^{\text {save }}$ and $W c^{\text {save }}$,found for Cases 5 , which is the most critical cases, compared to the PSO and GSA are respectively reduced by 1,$70743 ; 14,8309 ; 14,8305 \%$ and 5,59457 ; 48,$5297 ; 48,5298 \%$.

This result shows that the reduction of the $P_{\text {loss }}, P^{\text {save }}$ and $W c^{\text {save }}$ found by applying the proposed method compared to the other comparison methods (PSO and GSA) in the most critical case (Case 5) is significantly higher than that found in the base case (cases 1). This result shows the interest of hybridization between the PSO and GSA methods for solving complex optimization problems.

Table 10. Performance results of the GSA applied to the Algerian-114 bus.

\begin{tabular}{ccccccc}
\hline \multicolumn{7}{c}{ Algerian -114 bus (GSA) } \\
\hline & Case1 & Case 2 & Case & Case3-2 & Case4 & Case5 \\
\hline$P_{\text {loss }}$ & 0,5929 & 2,3332 & 0,305 & 1,2049 & 1,6798 & 1,7440 \\
$P^{C}$ save \% & 11,7303 & 7,1212 & 8,934 & 4,0713 & 18,5291 & 5,3230 \\
$W^{C}$ save $(\$)$ & 4141575,3960 & 9402720,8080 & 4265105,5680 & 20080094,1300 & 5153655,2450 \\
\hline
\end{tabular}

Table 11. Performance results of the PSO applied to the Algerian-114 bus.

\begin{tabular}{lllllll}
\hline \multicolumn{2}{c}{ Algerian -114bus (PSO) } & \multicolumn{7}{l}{} \\
\hline & Case1 & Case2 & Case3-1 & Case3-2 & Case4 & Case5 \\
\hline $\mathrm{P}_{\text {loss }}$ & 0,6000 & 2,3235 & 0,3163 & 1,1952 & 1,6598 & 1,6798 \\
$\mathrm{P}^{\mathrm{C}}$ save \% & 10,6997 & 7,5106 & 5,8377 & 4,8489 & 19,4991 & 8,8081 \\
$\mathrm{~W}^{\mathrm{C}}$ save $(\$)$ & 3770654,40 & 9916799,19 & 4231723,05 & 21131294,13 & 8527931,74 \\
\hline
\end{tabular}

Table 12. Performance results of the proposed method applied to the Algerian-114 bus.

\begin{tabular}{|c|c|c|c|c|c|c|}
\hline \multicolumn{7}{|c|}{ Algerian -114bus (PSO-GSA) } \\
\hline & Case1 & Case2 & Case3-1 & Case3-2 & Case4 & Case 5 \\
\hline$P_{\text {loss }}$ & 0,5905 & 2,3054 & 0,2907 & 1,1922 & 1,6298 & 1,6516 \\
\hline$P^{C}$ save $\%$ & 12,0943 & 8,2295 & 13,4587 & 5,0877 & 20,9541 & 10,3419 \\
\hline$W^{C}$ save $(\$)$ & 4270083,79 & 10866103,17 & \multicolumn{2}{|c|}{5734766,67} & 22708094,13 & 10012901,72 \\
\hline
\end{tabular}


Voltage stability analysis based on multi-objective optimal reactive power

Appendix B: The Algerian electric power system 114-bus.

Table B.1. Bus DATA

\begin{tabular}{|c|c|c|c|c|c|c|c|c|c|c|c|}
\hline Bus & Type & $\begin{array}{c}\mathrm{Pd} \\
(\mathrm{MW})\end{array}$ & $\begin{array}{c}\text { Qd } \\
\text { (Mvar) }\end{array}$ & Bus & Type & $\begin{array}{c}\mathrm{Pd} \\
(\mathrm{MW})\end{array}$ & $\begin{array}{c}\mathrm{Qd} \\
\text { (Mvar) }\end{array}$ & Bus & Type & $\begin{array}{c}\mathrm{Pd} \\
(\mathrm{MW}) \\
\end{array}$ & $\begin{array}{c}\text { Qd } \\
\text { (Mvar) }\end{array}$ \\
\hline 1 & 1 & 0 & 0 & 39 & 1 & 20 & 10 & 77 & 1 & 7 & 3 \\
\hline 2 & 1 & 36 & 17 & 40 & 1 & 21 & 10 & 78 & 1 & 13 & 7 \\
\hline 3 & 1 & 64 & 31 & 41 & 1 & 53 & 32 & 79 & 1 & 14 & 7 \\
\hline 4 & 3 & 210 & 150 & 42 & 1 & 0 & 0 & 80 & 2 & 157 & 107 \\
\hline 5 & 2 & 335 & 250 & 43 & 1 & 31 & 18 & 81 & 1 & 0 & 0 \\
\hline 6 & 1 & 78 & 37 & 44 & 1 & 0 & 0 & 82 & 1 & 75 & 36 \\
\hline 7 & 1 & 55 & 26 & 45 & 1 & 12 & 6 & 83 & 2 & 70 & 51 \\
\hline 8 & 1 & 50 & 24 & 46 & 1 & 0 & 0 & 84 & 1 & 46 & 34 \\
\hline 9 & 1 & 40 & 19 & 47 & 1 & 21 & 10 & 85 & 1 & 45 & 22 \\
\hline 10 & 1 & 42 & 21 & 48 & 1 & 0 & 0 & 86 & 1 & 0 & 0 \\
\hline 11 & 2 & 96 & 47 & 49 & 1 & 13 & 6 & 87 & 1 & 32 & 15 \\
\hline 12 & 1 & 31 & 15 & 50 & 1 & 4 & 2 & 88 & 1 & 46 & 22 \\
\hline 13 & 1 & 13 & 6 & 51 & 1 & 1 & 1 & 89 & 1 & 34 & 17 \\
\hline 14 & 1 & 136 & 65 & 52 & 2 & 56 & 27 & 90 & 1 & 18 & 9 \\
\hline 15 & 2 & 0 & 0 & 53 & 1 & 16 & 8 & 91 & 1 & 44 & 21 \\
\hline 16 & 1 & 0 & 0 & 54 & 1 & 21 & 10 & 92 & 1 & 10 & 5 \\
\hline 17 & 2 & 0 & 0 & 55 & 1 & 18 & 9 & 93 & 1 & 0 & 0 \\
\hline 18 & 1 & 0 & 0 & 56 & 1 & 33 & 20 & 94 & 1 & 48 & 23 \\
\hline 19 & 2 & 11 & 5 & 57 & 1 & 35 & 21 & 95 & 1 & 35 & 17 \\
\hline 20 & 1 & 14 & 9 & 58 & 1 & 0 & 0 & 96 & 1 & 0 & 0 \\
\hline 21 & 1 & 70 & 52 & 59 & 1 & 36 & 17 & 97 & 1 & 42 & 20 \\
\hline 22 & 2 & 42 & 25 & 60 & 1 & 0 & 0 & 98 & 2 & 13 & 6 \\
\hline 23 & 1 & 23 & 11 & 61 & 1 & 27 & 13 & 99 & 1 & 105 & 50 \\
\hline 24 & 1 & 60 & 36 & 62 & 1 & 22 & 11 & 100 & 2 & 33 & 16 \\
\hline 25 & 1 & 17 & 8 & 63 & 1 & 49 & 29 & 101 & 2 & 50 & 24 \\
\hline 26 & 1 & 55 & 26 & 64 & 1 & 0 & 0 & 102 & 1 & 34 & 16 \\
\hline 27 & 1 & 0 & 0 & 65 & 1 & 11 & 5 & 103 & 1 & 66 & 32 \\
\hline 28 & 1 & 0 & 0 & 66 & 1 & 35 & 21 & 104 & 1 & 18 & 9 \\
\hline 29 & 1 & 37 & 18 & 67 & 1 & 10 & 5 & 105 & 1 & 0 & 0 \\
\hline 30 & 1 & 30 & 15 & 68 & 1 & 11 & 5 & 106 & 1 & 64 & 31 \\
\hline 31 & 1 & 0 & 0 & 69 & 1 & 20 & 10 & 107 & 1 & 65 & 37 \\
\hline 32 & 1 & 40 & 24 & 70 & 1 & 7 & 3 & 108 & 1 & 22 & 11 \\
\hline 33 & 1 & 29 & 14 & 71 & 1 & 36 & 22 & 109 & 2 & 37 & 18 \\
\hline 34 & 1 & 29 & 14 & 72 & 1 & 0 & 0 & 110 & 1 & 13 & 6 \\
\hline 35 & 1 & 33 & 16 & 73 & 1 & 36 & 22 & 111 & 2 & 94 & 56 \\
\hline 36 & 1 & 17 & 8 & 74 & 1 & 0 & 0 & 112 & 1 & 24 & 12 \\
\hline 37 & 1 & 11 & 5 & 75 & 1 & 0 & 0 & 113 & 1 & 23 & 11 \\
\hline 38 & 1 & 20 & 10 & 76 & 1 & 12 & 6 & 114 & 1 & 24 & 12 \\
\hline
\end{tabular}


Youssouf Amrane, et al.

Table B.2. Generator DATA.

\begin{tabular}{cccccccc}
\hline Bus & $\begin{array}{c}\text { Pg } \\
(\mathrm{MW})\end{array}$ & $\begin{array}{c}\text { Qg } \\
(\mathrm{MVar})\end{array}$ & $\begin{array}{c}\text { Qmax } \\
(\text { MVar })\end{array}$ & $\begin{array}{c}\text { Qmin } \\
(\mathrm{MVar})\end{array}$ & $\begin{array}{c}\text { Vg } \\
(\mathrm{pu})\end{array}$ & $\begin{array}{c}\text { Pmax } \\
(\mathrm{MW})\end{array}$ & $\begin{array}{c}\text { Pmin } \\
(\mathrm{MW})\end{array}$ \\
\hline 4 & 750 & 0 & 400 & -20 & 1.07 & 1200 & 0 \\
5 & 450 & 0 & 200 & -20 & 1.05 & 650 & 0 \\
11 & 100 & 0 & 100 & -50 & 1.05 & 150 & 0 \\
15 & 100 & 0 & 100 & 0 & 1.04 & 150 & 0 \\
17 & 450 & 0 & 400 & 0 & 1.08 & 600 & 0 \\
19 & 115 & 0 & 60 & 0 & 1.03 & 150 & 0 \\
52 & 115 & 0 & 50 & 0 & 1.04 & 150 & 0 \\
22 & 115 & 0 & 50 & 0 & 1.05 & 150 & 0 \\
80 & 115 & 0 & 60 & 0 & 1.08 & 150 & 0 \\
83 & 100 & 0 & 200 & -50 & 1.05 & 150 & 0 \\
98 & 100 & 0 & 50 & 0 & 1.05 & 150 & 0 \\
100 & 200 & 0 & 270 & 0 & 1.08 & 250 & 0 \\
101 & 200 & 0 & 200 & -50 & 1.08 & 250 & 0 \\
109 & 100 & 0 & 100 & -50 & 1.05 & 150 & 0 \\
111 & 100 & 0 & 155 & -50 & 1.02 & 150 & 0 \\
\hline
\end{tabular}


Table B 3. Branch DATA.

\begin{tabular}{|c|c|c|c|c|c|c|c|c|c|c|c|}
\hline Fbus & Tbus & $\mathbf{R}$ & $\mathrm{V}$ & B & Rate & Fbus & Tbus & $\mathbf{R}$ & $x$ & B & Rate \\
\hline 2 & 1 & 0.0085 & 0.0403 & 0.0303 & 250 & 107 & 101 & 0.0334 & 0.1577 & 0.1189 & 250 \\
\hline 6 & 1 & 0.0122 & 0.0578 & 0.0436 & 250 & 64 & 97 & 0.0178 & 0.0654 & 0.0470 & 200 \\
\hline 2 & 6 & 0.0140 & 0.0498 & 0.0355 & 200 & 72 & 96 & 0.0152 & 0.0540 & 0.0386 & 200 \\
\hline 4 & 42 & 0.0274 & 0.1295 & 0.0976 & 250 & 96 & 98 & 0.0203 & 0.0720 & 0.0515 & 200 \\
\hline 4 & 42 & 0.0139 & 0.0122 & 0.1474 & 450 & 96 & 95 & 0.0015 & 0.0070 & 0.0053 & 200 \\
\hline 4 & 3 & 0.0033 & 0.0158 & 0.0482 & 500 & 18 & 22 & 0.0290 & 0.1397 & 0.0017 & 80 \\
\hline 5 & 3 & 0.0028 & 0.0189 & 0.0294 & 450 & 18 & 37 & 0.0256 & 0.1233 & 0.0015 & 80 \\
\hline 5 & 4 & 0.0018 & 0.0126 & 0.0197 & 450 & 37 & 22 & 0.0171 & 0.0822 & 0.0010 & 80 \\
\hline 4 & 7 & 0.0144 & 0.0678 & 0.0512 & 250 & 19 & 26 & 0.0058 & 0.0077 & 0.0017 & 60 \\
\hline 15 & 16 & 0.0038 & 0.0135 & 0.0097 & 200 & 19 & 26 & 0.0058 & 0.0077 & 0.0017 & 60 \\
\hline 16 & 3 & 0.0041 & 0.0144 & 0.0103 & 200 & 19 & 34 & 0.0019 & 0.0126 & 0.0001 & 80 \\
\hline 16 & 14 & 0.0013 & 0.0045 & 0.0032 & 200 & 20 & 18 & 0.1348 & 0.2944 & 0.0013 & 50 \\
\hline 8 & 42 & 0.0171 & 0.0629 & 0.0454 & 200 & 20 & 24 & 0.0376 & 0.1390 & 0.0006 & 40 \\
\hline 8 & 4 & 0.0184 & 0.0870 & 0.0657 & 250 & 20 & 24 & 0.0368 & 0.1361 & 0.0006 & 40 \\
\hline 10 & 7 & 0.0150 & 0.0709 & 0.0535 & 250 & 20 & 29 & 0.0319 & 0.1178 & 0.0005 & 40 \\
\hline 10 & 11 & 0.0228 & 0.1076 & 0.0811 & 250 & 20 & 35 & 0.0428 & 0.1528 & 0.0006 & 40 \\
\hline 7 & 6 & 0.0157 & 0.0740 & 0.0558 & 250 & 35 & 29 & 0.0458 & 0.1639 & 0.0007 & 40 \\
\hline 11 & 42 & 0.0170 & 0.0806 & 0.0608 & 250 & 20 & 32 & 0.0708 & 0.2365 & 0.0010 & 60 \\
\hline 6 & 3 & 0.0288 & 0.1012 & 0.0730 & 200 & 22 & 32 & 0.0342 & 0.1142 & 0.0005 & 60 \\
\hline 9 & 2 & 0.0042 & 0.0284 & 0.0442 & 450 & 22 & 24 & 0.0239 & 0.0799 & 0.0003 & 60 \\
\hline 9 & 3 & 0.0088 & 0.0600 & 0.0933 & 450 & 22 & 24 & 0.0239 & 0.0799 & 0.0003 & 60 \\
\hline 13 & 12 & 0.0501 & 0.2365 & 0.1784 & 250 & 23 & 30 & 0.0239 & 0.0799 & 0.0003 & 60 \\
\hline 10 & 13 & 0.0464 & 0.2190 & 0.1652 & 250 & 23 & 36 & 0.0136 & 0.0457 & 0.0002 & 60 \\
\hline 17 & 21 & 0.0065 & 0.0244 & 0.0176 & 200 & 36 & 30 & 0.0273 & 0.0913 & 0.0004 & 60 \\
\hline 17 & 21 & 0.0073 & 0.0278 & 0.0202 & 200 & 33 & 18 & 0.0205 & 0.0685 & 0.0003 & 60 \\
\hline 17 & 72 & 0.0197 & 0.0732 & 0.0530 & 200 & 32 & 33 & 0.0239 & 0.0799 & 0.0003 & 60 \\
\hline 17 & 27 & 0.0046 & 0.0237 & 0.1003 & 300 & 26 & 25 & 0.0139 & 0.0517 & 0.0002 & 30 \\
\hline 17 & 31 & 0.0061 & 0.0311 & 0.0617 & 350 & 24 & 25 & 0.0164 & 0.0608 & 0.0003 & 60 \\
\hline 31 & 28 & 0.0017 & 0.0088 & 0.0746 & 300 & 26 & 34 & 0.0049 & 0.0318 & 0.0002 & 60 \\
\hline 17 & 64 & 0.0198 & 0.0727 & 0.0525 & 200 & 29 & 26 & 0.0119 & 0.0158 & 0.0034 & 60 \\
\hline 21 & 44 & 0.0240 & 0.0861 & 0.0615 & 200 & 29 & 39 & 0.0126 & 0.0820 & 0.0004 & 80 \\
\hline 60 & 31 & 0.0037 & 0.0253 & 0.0393 & 450 & 38 & 34 & 0.0047 & 0.0307 & 0.0002 & 80 \\
\hline 21 & 60 & 0.0056 & 0.0263 & 0.0198 & 250 & 18 & 73 & 0.1557 & 0.3427 & 0.0015 & 50 \\
\hline 60 & 44 & 0.0122 & 0.0578 & 0.0436 & 250 & 18 & 73 & 0.0854 & 0.3028 & 0.0012 & 60 \\
\hline 58 & 44 & 0.0121 & 0.0569 & 0.0429 & 250 & 62 & 18 & 0.0508 & 0.1941 & 0.0008 & 60 \\
\hline 72 & 101 & 0.0213 & 0.1007 & 0.0760 & 250 & 20 & 52 & 0.0873 & 0.2162 & 0.0011 & 50 \\
\hline 72 & 58 & 0.0183 & 0.0863 & 0.0651 & 250 & 20 & 52 & 0.0875 & 0.2167 & 0.0011 & 50 \\
\hline 58 & 75 & 0.0148 & 0.0701 & 0.0528 & 250 & 54 & 59 & 0.1188 & 0.3063 & 0.0015 & 50 \\
\hline 75 & 107 & 0.0185 & 0.0876 & 0.0660 & 250 & 52 & 59 & 0.0360 & 0.1014 & 0.0005 & 50 \\
\hline 75 & 74 & 0.0006 & 0.0026 & 0.0026 & 250 & 57 & 51 & 0.1227 & 0.4098 & 0.0018 & 60 \\
\hline 44 & 42 & 0.0248 & 0.0903 & 0.0649 & 200 & 57 & 77 & 0.1366 & 0.4566 & 0.0020 & 60 \\
\hline 44 & 42 & 0.0183 & 0.0864 & 0.0651 & 250 & 52 & 53 & 0.0937 & 0.1788 & 0.0007 & 35 \\
\hline 42 & 48 & 0.0074 & 0.0506 & 0.0786 & 450 & 53 & 54 & 0.0937 & 0.1788 & 0.0007 & 35 \\
\hline 48 & 44 & 0.0025 & 0.0158 & 0.0245 & 450 & 52 & 30 & 0.0722 & 0.1789 & 0.0009 & 50 \\
\hline
\end{tabular}


Youssouf Amrane, et al.

\begin{tabular}{|c|c|c|c|c|c|c|c|c|c|c|c|}
\hline Fbus & Tbus & $\mathbf{R}$ & $\mathbf{x}$ & B & Rate & Fbus & Tbus & $\mathbf{R}$ & $\mathbf{x}$ & B & Rate \\
\hline 71 & 70 & 0.1599 & 0.3148 & 0.0013 & 35 & 98 & 97 & 0.0121 & 0.0448 & 0.0325 & 200 \\
\hline 40 & 41 & 0.0586 & 0.1623 & 0.0008 & 50 & 99 & 100 & 0.0231 & 0.1089 & 0.0821 & 250 \\
\hline 40 & 50 & 0.1343 & 0.3645 & 0.0016 & 35 & 87 & 100 & 0.0102 & 0.0694 & 0.0105 & 450 \\
\hline 71 & 69 & 0.1093 & 0.3653 & 0.0016 & 60 & 100 & 84 & 0.0065 & 0.0442 & 0.0687 & 450 \\
\hline 70 & 68 & 0.1204 & 0.2180 & 0.0009 & 35 & 84 & 80 & 0.0074 & 0.0506 & 0.0786 & 450 \\
\hline 43 & 46 & 0.1025 & 0.3425 & 0.0015 & 60 & 86 & 81 & 0.0055 & 0.0379 & 0.0589 & 450 \\
\hline 51 & 43 & 0.2067 & 0.3556 & 0.0015 & 35 & 98 & 99 & 0.0163 & 0.0580 & 0.0414 & 200 \\
\hline 54 & 55 & 0.1196 & 0.3996 & 0.0018 & 60 & 101 & 102 & 0.0116 & 0.0547 & 0.0413 & 250 \\
\hline 55 & 43 & 0.1708 & 0.5708 & 0.0025 & 60 & 99 & 102 & 0.0116 & 0.0547 & 0.0413 & 250 \\
\hline 73 & 62 & 0.0410 & 0.1370 & 0.0006 & 60 & 99 & 101 & 0.0111 & 0.0759 & 0.1179 & 450 \\
\hline 73 & 67 & 0.3347 & 0.7007 & 0.0031 & 40 & 98 & 94 & 0.0357 & 0.1275 & 0.0918 & 200 \\
\hline 68 & 67 & 0.1648 & 0.3569 & 0.0015 & 40 & 94 & 82 & 0.0056 & 0.0263 & 0.0198 & 250 \\
\hline 29 & 26 & 0.0119 & 0.0158 & 0.0034 & 60 & 92 & 93 & 0.1624 & 0.4088 & 0.0099 & 60 \\
\hline 73 & 66 & 0.1623 & 0.5752 & 0.0023 & 60 & 93 & 91 & 0.0304 & 0.1074 & 0.0021 & 60 \\
\hline 63 & 66 & 0.0683 & 0.2283 & 0.0010 & 60 & 93 & 91 & 0.0379 & 0.1342 & 0.0027 & 60 \\
\hline 63 & 65 & 0.0557 & 0.1861 & 0.0008 & 60 & 90 & 89 & 0.0776 & 0.2400 & 0.0052 & 60 \\
\hline 63 & 65 & 0.0557 & 0.1861 & 0.0008 & 60 & 88 & 89 & 0.1354 & 0.4100 & 0.0089 & 60 \\
\hline 56 & 54 & 0.1025 & 0.3425 & 0.0015 & 60 & 90 & 93 & 0.1852 & 0.3189 & 0.0068 & 60 \\
\hline 57 & 56 & 0.1196 & 0.3996 & 0.0018 & 60 & 103 & 110 & 0.0185 & 0.0876 & 0.0660 & 250 \\
\hline 57 & 56 & 0.1196 & 0.3996 & 0.0018 & 60 & 110 & 112 & 0.0185 & 0.0876 & 0.0660 & 250 \\
\hline 47 & 50 & 0.1196 & 0.3996 & 0.0018 & 60 & 103 & 114 & 0.0419 & 0.1979 & 0.1493 & 250 \\
\hline 47 & 46 & 0.0342 & 0.1142 & 0.0005 & 60 & 109 & 108 & 0.0148 & 0.0701 & 0.0528 & 250 \\
\hline 67 & 66 & 0.1128 & 0.2794 & 0.0014 & 50 & 109 & 107 & 0.0388 & 0.1833 & 0.1382 & 250 \\
\hline 49 & 41 & 0.1265 & 0.4225 & 0.0019 & 50 & 112 & 114 & 0.0190 & 0.0896 & 0.0675 & 250 \\
\hline 19 & 78 & 0.0042 & 0.0055 & 0.0012 & 60 & 112 & 111 & 0.0297 & 0.1402 & 0.1057 & 250 \\
\hline 19 & 79 & 0.0105 & 0.0139 & 0.0030 & 60 & 113 & 111 & 0.0167 & 0.0787 & 0.0608 & 250 \\
\hline 59 & 61 & 0.0513 & 0.1816 & 0.0007 & 60 & 80 & 88 & 0.0123 & 0.3140 & 0.0000 & 400 \\
\hline 45 & 46 & 0.0171 & 0.0605 & 0.0002 & 60 & 81 & 90 & 0.0062 & 0.1452 & 0.0000 & 240 \\
\hline 85 & 87 & 0.0158 & 0.0745 & 0.0562 & 250 & 86 & 93 & 0.0012 & 0.0742 & 0.0000 & 240 \\
\hline 85 & 86 & 0.0139 & 0.0657 & 0.0495 & 250 & 42 & 41 & 0.0012 & 0.0742 & 0.0000 & 240 \\
\hline 85 & 81 & 0.0099 & 0.0467 & 0.0352 & 250 & 58 & 57 & 0.0012 & 0.0742 & 0.0000 & 240 \\
\hline 87 & 106 & 0.0105 & 0.0495 & 0.0373 & 250 & 44 & 43 & 0.0029 & 0.1053 & 0.0000 & 120 \\
\hline 87 & 82 & 0.0056 & 0.0266 & 0.0200 & 250 & 60 & 59 & 0.0014 & 0.0516 & 0.0000 & 360 \\
\hline 87 & 99 & 0.0322 & 0.1249 & 0.0909 & 200 & 64 & 63 & 0.0019 & 0.0700 & 0.0000 & 180 \\
\hline 103 & 105 & 0.0130 & 0.0613 & 0.0462 & 250 & 72 & 71 & 0.0012 & 0.0742 & 0.0000 & 240 \\
\hline 105 & 101 & 0.0171 & 0.0806 & 0.0608 & 250 & 17 & 18 & 0.0014 & 0.0516 & 0.0000 & 360 \\
\hline 105 & 104 & 0.0015 & 0.0070 & 0.0053 & 250 & 21 & 20 & 0.0016 & 0.0525 & 0.0000 & 240 \\
\hline 103 & 106 & 0.0208 & 0.0983 & 0.0741 & 250 & 27 & 26 & 0.0024 & 0.1484 & 0.0000 & 120 \\
\hline 81 & 82 & 0.0303 & 0.1075 & 0.0768 & 200 & 28 & 26 & 0.0024 & 0.1484 & 0.0000 & 120 \\
\hline 80 & 82 & 0.0319 & 0.1129 & 0.0807 & 200 & 31 & 30 & 0.0007 & 0.0495 & 0.0000 & 360 \\
\hline 80 & 84 & 0.0191 & 0.0676 & 0.0483 & 200 & 48 & 47 & 0.0012 & 0.0742 & 0.0000 & 240 \\
\hline 84 & 83 & 0.0051 & 0.0180 & 0.0129 & 200 & 74 & 76 & 0.0089 & 0.3340 & 0.0000 & 40 \\
\hline 82 & 83 & 0.0191 & 0.0676 & 0.0483 & 200 & & & & & & \\
\hline 100 & 98 & 0.0102 & 0.0598 & 0.0754 & 250 & & & & & & \\
\hline 100 & 97 & 0.0111 & 0.0759 & 0.1179 & 450 & & & & & & \\
\hline
\end{tabular}




\section{Conclusion}

The Hybrid Particle Swarm Optimization and Gravitational Search have been used for solving the reactive power planning using SVC's device. Various critical situations are simulated to prove the effectiveness of the proposed algorithm and to ensure viability of the power system in contingency scenarios. The locations of the SVC's devices considering voltage security are determined using three different stability indexes namely, Fast Voltage Stability Index (FVSI), Line stability index ( $L m n)$ and Line Stability Factor $(L P Q)$.

The simulation results show the high performance of PSOSGA algorithm on minimizing the transmission power losses and on improving the real power and annual cost savings. The analyses of the results are very promising since the main objectives of the proposed technique were achieved:

- State and control variables were brought to their range limits.

- Voltage stabilityis ensured in the most critical bus in the system by installing the compensation devices.

- Minimum of SVC's devices amount.

- Minimum of transmission active power losses.

- The best real power saving and the annual cost saving.

\section{Acknowledgement}

We would like to acknowledge the support of the Algerian company of Electricity SONELGAZ who supported this work.

\section{References}

[1]. Y. Amrane, M. Boudour, et M. Belazzoug. A new hybrid technique for power systems multi-facts optimization design. International Transactions on Electrical Energy Systems, 2014.

[2]. M. Basu, Multi-objective optimal power flow with FACTS devices, Energy Conversion and Management, Vol.52, pp.903-910, 2011.

[3].

[4]. K. Iba, H. Suzuki, K.-I. Suzuki, K. Suzuki.: Practical reactive power allocation/operation planning using successive linear programming. IEEE Trans. on PAS, vol. 3, no. 2, pp.558566, May 1988.

[5]. M. Belazzoug, M. Boudour and A. Hellal.: New reactive power sources dispatch applied to the IEEE 57 nodes. The Int. J. for Computation and Mathematics in Electrical and Electronic Engineering, Vol. 27, No. 5, pp.1192-1211, 2008.

[6]. N. Grudinin.: reactive power optimization using successive quadratic programming method. IEEE Transactions on Power Systems, Vol. 13, no. 4, November 1998.

[7]. Y.Amrane, M.Boudour, A. A. Ladjici, A.Elmaouhab, Optimal VAR control for real power loss minimization using differential evolution algorithm, Electrical Power and Energy Systems, Vol.66,pp.262-271, 2015.

[8]. Y. Amrane, M. Boudour, M.Belazzoug, A new Optimal reactive power planning based on Differential Search Algorithm, Electrical Power and Energy Systems, Vol 64, pp.551-561, 2015.

[9]. Youcef Amrane, Mohamed Boudour, Particle Swarm Optimization Based Reactive Power Planning for Line Stability Improvement, 3rd International Conference on Control, Engineering \& Information Technology, pp. 1 - 7 May 2015.

[10]. Amrane, Y., Boudour. M, Optimal reactive power dispatch based on particle swarm optimization approach applied to the Algerian electric power system, Multi-Conference on Systems, Signals \& Devices (SSD), 2014 11thInternational, pp. 1 - 6, Feb. 2014.

[11]. Gonggui Chen, Lilan Liu, Peizhu Song, Yangwei Dua,Chaotic improved PSO-based multiobjective optimization for minimization of power losses and $\mathrm{L}$ index in power systems, Energy Conversion and Management, Vol.86 ,pp.548-560, 2014. 
[12]. Belkacem Mahdad, K. Srairi,Chaotic improved PSO-based multi-objective optimization for minimization of power losses and L index in power systems, Energy Conversion and Management, Vol. pp.86 548-560, (2014).

[13]. Ruiz, Pablo, and Peter W. Sauer. "Voltage and reactive power estimation for contingency analysis using sensitivities." Power Systems, IEEE Transactions on, Vol.22, no.2, pp.639647, 2007.

[14]. Taylor, D. G., and L. J. Maahs. "A reactive contingency analysis algorithm using MW and MVAR distribution factors." Power Systems, IEEE Transactions on Vol.6,no.1 ,pp.349355, 1991.

[15]. Mittal, Anshul, et al. "Real time contingency analysis for power grids." Euro-Par 2011 Parallel Processing. Springer Berlin Heidelberg, pp.303-315, 2011.

[16]. Greyson, Kenedy Aliila. "Contingency analysis model for power systems based on agents." (2010) :http://sutir.sut.ac.th:8080/sutir/handle/123456789/3712.

[17]. Habibollah Raoufi, Mohsen Kalantar,Reactive power rescheduling with generator ranking for voltage stability improvement, Energy Conversion and Management, Vol.50 ,pp.1129$1135,2009$.

[18]. Xiong Hugang, Cheng Haozhong, Li Haiyu,Optimal reactive power flow incorporating static voltage stability based on multi-objective adaptive immune algorithm, Energy Conversion and Management, Vol.49, pp.1175-1181, 2008.

[19]. Musinin, I and Abdul Rahman T.K .:Novel Fast Voltage Stability Index (FVSI) for Voltage Stability Analysis in Power Transmission System. IEEE, 2002 Student conference Research and Development, Shah Alam Malaysia, pp 7803-7565, 2002.

[20]. M Moghavemmi, and F M Omar, "Technique for Contingency Monitoring and Voltage Collapse Prediction," IEE Proceeding on Generation, Transmission and Distribution, vol. 145, no. 6, pp634 - 640,1998.

[21]. A Mobamed, G B Jasmon and S Yusoff, "A Static Voltage Collapse Indicator Using Line Stability Factors," Journal of Industrial Technology, vol. I, no. 1. Pt C, pp 73-85, 1989.

[22]. S. Mirjalili, S.Z. Mohd Hashim, "A New Hybrid PSOGSA Algorithm for Function Optimization, in IEEE International Conference on Computer and Information Application” ICCIA 2010), pp. 374-377, China, 2010.

[23]. J. Kennedy, Particle swarm optimization. Proceedings of the IEEE International Conference on Neural Networks, vol. IV, pp. 1942- 1948, 1995.

[24]. E. Rashedi, H. Nezamabadi-pour, S. Saryazdi, "GSA: A gravitational search algorithm," Information Sciences, vol. 179, pp. 2232-2248, 2009.

[25]. Lai, Loi Lei, and J. T. Ma. "Application of evolutionary programming to reactive power planning-comparison with nonlinear programming approach." Power Systems, IEEE Transactions on vol.12, no.1 ,pp.198-206, 1997.

[26]. Kheirizad, I., Mohammadi, A., \& Varahram, M. H. (2008). A novel algorithm for optimal location of FACTS devices in power system planning. Journal of Electrical Engineering \& Technology, 3(2), 177-183.

[27]. Precup, R. E., David, R. C., Stinean, A. I., Radac, M. B., \& Petriu, E. M. (2014, June). Adaptive hybrid Particle Swarm Optimization-Gravitational Search Algorithm for fuzzy controller tuning. In Innovations in Intelligent Systems and Applications (INISTA) Proceedings, 2014 IEEE International Symposium on (pp. 14-20). IEEE.

[28]. Mallick, S., Ghoshal, S. P., Acharjee, P., \& Thakur, S. S. (2013). Optimal static state estimation using improved particle swarm optimization and gravitational search algorithm. International Journal of Electrical Power \& Energy Systems, 52, 254-265.

[29]. K. Lenin, B. Ravindranath Reddy and M. Surya Kalavathi, A New Hybrid PSOGSA Algorithm for Solving Optimal Reactive Power Dispatch Problem, International Journal of Mechatronics, Electrical and Computer Technology, Vol. 4(10), Jan. 2014, pp. 111-125, ISSN: 2305-0543. 
[30]. Purcaru, Constantin, Precup, R.-E., Iercan, Daniel, et al.Hybrid PSO-GSA robot path planning algorithm in static environments with danger zones. In : System Theory, Control and Computing (ICSTCC), 2013 17th International Conference. IEEE, 2013. p. 434-439.

[31]. Mangaiyarkarasi, S. P., \& Raja, T. S. R. (2014). Optimal Location and Sizing of Multiple Static VAr Compensators for Voltage Risk Assessment Using Hybrid PSO-GSA Algorithm. Arabian Journal for Science and Engineering, 39(11), 7967-7980.

[32]. Ashouri, M., \& Hosseini, S. M. (2013). Application of New Hybrid Particle Swarm Optimization and Gravitational Search Algorithm for Non Convex Economic Load Dispatch Problem. Journal of Advances in Computer Research, 4(2), 41-51.

[33]. Hardiansyah A Novel Hybrid PSO-GSA Method for Non-convex Economic Dispatch Problems, I.J. Information Engineering and Electronic Business, 2013, 5, 1-9

[34]. Jiang, S., Ji, Z., \& Shen, Y. (2014). A novel hybrid particle swarm optimization and gravitational search algorithm for solving economic emission load dispatch problems with various practical constraints. International Journal of Electrical Power \& Energy Systems, $55,628-644$.

List of symbols

$f_{\text {VAR: }}$ The objective function of the compensation devices investment cost;

$f_{W c}$ : The objective function of the cost of energy losses ;

$G$ and $H$ : Equality and inequality constraints of the system;

$U: T$ he vector of controls variables and $X$ is the vector of state variables;

$C_{f:}$ The fixed installation cost of the reactive power sources at the $i^{\text {th }}$ bus $(1771.59(\$))$;

$C_{c i}$ : The cost per MVAR of the compensation devices at the $i^{\text {th }}$ bus (5314.8 (\$/MVAR));

$Q_{c i}$ : The reactive power compensation at the $i^{\text {th }}$ bus (MVAR);

$N_{V A R}$ : The number of installed compensation devices;

$f_{\text {Ploss: }}$ The objective function of real power losses problem;

$V_{i}, V_{j}$ : The voltage magnitudes;

$G_{k}$ : The conductance of branch $k$;

$\theta_{i}, \theta_{j}$ : The voltage angel at buses $i$ and $j$;

$N_{L i}$ : The number of transmission lines; $h$ is the energy cost $(0.06(\$ / k W h))$;

$P_{D i}, Q_{D i}:$ Real and reactive power at bus $i$;

$P_{G i}, Q_{G i}$ : Real and reactive powers of the $i^{\text {th }}$ generator;

$V_{i}$ : The voltage magnitude at bus $I$;

$N_{\text {Bus: }}$ : The number of buses;

$G_{i j}, B_{i j}$ : The conductance and susceptance between $i$ and $j$;

$\theta_{i j}$ : The phase angle difference between the voltages at $i$ and $j$;

$\theta_{j i}$ : The phase angle difference between the voltages at $j$ and $i$;

$N_{\text {bus: }}$ : The number buses;

$N_{G}$ : The number of generators;

$N_{c}$ : The number of switchable VAR sources;

$N_{T}$ : The number of transformers;

$N_{\text {load }}$ : The number of load buses and $N_{L i}$ the number of transmission lines;

$Z$ : The line impedance;

$X$ : The line reactance;

$Q_{j}$ : The reactive power flow at the receiving end ;

$V_{i}$ : The sending end voltage;

$\mathrm{X}$ : The line reactance;

$\mathrm{Q}_{\mathrm{r}}$ : The reactive power at the receiving end;

$\mathrm{V}_{\mathrm{i}}$ : The sending end voltage;

$\Theta$ : The line impedance angle; 
$\delta:$ The angle difference between the supply voltage and the receiving voltage;

$t:$ The current epoch ;

$V_{i}(t)$ : The velocity of agent $i$ at iteration $t$

$c_{j}$ ': A weighting factor;

$w$ : The weighting function;

rand: A random number between interval $[0,1]$;

$a c_{i}(t)$ : The acceleration of agent $i$ at iteration $t$;

gbest: The best solution;

$M_{a j}$ : The active gravitational mass related to agent $j$;

$M_{p i}$ : The passive gravitational mass related to agent $I$;

$G(t)$ : The gravitational constant at time $t$;

$\varepsilon$ : A small constant;

$R_{i j}(t)$ : The Euclidian distance between two agents $i$ and $j$;

$\alpha, G_{0}$ : Descending coefficient and initial value respectively;

iter: The current iteration;

maxiter: The maximum number of iterations ;

rand $_{j}:$ A random number in the interval $[0,1]$;

$t:$ A specific time;

$M_{i i}$ : The mass of object;

$\sigma_{v_{i}}$ : The penalty factors for the bus voltage limit violation;

$\sigma_{Q_{G i}}$ : The penalty factors for the generator reactive power limit violation;

$\sigma_{S_{i}^{t}}:$ The penalty factors for line flow violation; 


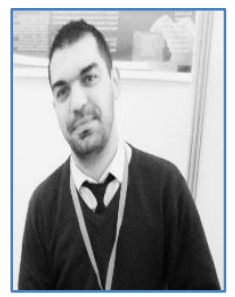

Youssouf Amrane received his Master's and $\mathrm{PhD}$ in Electrical Engineering from the Faculty of Electrical Engineering and Computing; University of Sciences and Technology Houari Boumediene (USTHB) of Algiers in 2011 and 2014, respectively. Currently, he is an Associate Professor at the Department of Electrical Engineering and Computing of USTHB. His current research interest includes power system computing and simulation, FACTS devices, optimization techniques, power system dynamics and power system economics and renewable energy.

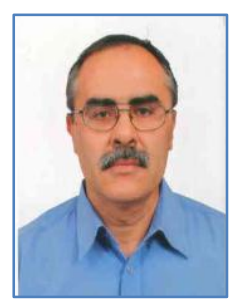

Ali Elmaouhab received his Engineering degree from the Annaba University, Algeria in 1985, MPhil degree from the Queen Mary College, University of London, England in Electrical Engineering in 1988 and PhD degree from the University of Science and Technology Houari Boumediene (USTHB) of Algiers in 2014. He is a Lecturer at the USTHB since 1988. Hid field of interest is integration and impact of wind generator in electrical network.

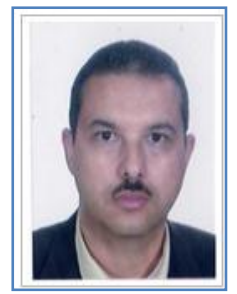

Mohamed Boudour received the B.Sc, M.Sc and $\mathrm{PhD}$ in Electrical Engineering from the Polytechnic School of Algiers in 1991, 1994 and 2004, respectively. Since January 1994, he has been with the University of Sciences and Technology Houari Boumediene of Algiers (USTHB) as a teacher and researcher. He was awarded as a Fulbright fellowship in the University of Washington, Seattle (USA) from 2005-2006. He is a member of the executive committee of ARELEC (Algerian CIGRE) and IEEE Senior Member since 2007. His main interests are Power Systems Stability and Control using intelligent programming, integration of renewable energy sources in smart grids. He is currently the Director of Electrical and Industrial System Laboratory.

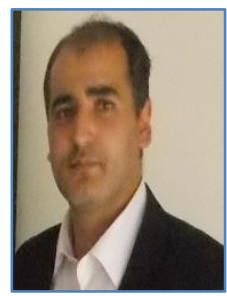

Ahmed Amine Ladjici received his BS and MS in Electrical Engineering from the Polytechnical School of Algiers in 2002 and 2005, respectively. In 2011, he received his $\mathrm{PhD}$ in Electrical Engineering from the University of Sciences and Technologies Houari Boumedien. Currently, he is an Associate Professor from the Department of Electrical Engineering and Computing of USTHB. His research area includes power system computing and simulation, power system dynamics and power system economics. 